\title{
THE ECOLOGICAL ROLE OF FIRE IN NATURAL CONIFER FORESTS OF WESTERN AND NORTHERN NORTH AMERICA-INTRODUCTION
}

\author{
Herbert E. Wright, Jr., ${ }^{1}$ and Miron L. Heinselman ${ }^{2}$ \\ ${ }^{1}$ Limnological Research Center, University of Minnesota, \\ 500 Pillsbury Drive SE, Minneapolis, Minnesota 55455, USA \\ 2 North Central Forest Experimental Station, US Forest Service, \\ 1992 Folwell Avenue, St. Paul, Minnesota 55101, USA
}

Forest fires have been the bane of forest managers, resource analysts, and the public ever since the timberlands of the Great Lakes area and the western mountains were opened for exploitation or designated for preservation. The psychological stage was set during the early years of commercial timber cutting, when escaped slash fires burned several towns to the ground, killed thousands of people, and destroyed the young regeneration and remnants of uncut forest on literally millions of acres. Whether the forest was to be cut for timber or set aside for preservation as a natural feature, it was assumed that fires were destructive and should be prevented at all costs. Laws were passed to require the disposal of slash by safe methods in timbered areas, but insufficient care was used and fires continued to escape.

When the public forests were established in the early years of this century, one of the first actions was the creation of a system for the detection and suppression of fires. Public forests became dotted with fire towers, and over the years the lore and loneliness of the fireguard became legend.

Fire-suppression methods changed as technology developed. The catastrophes common in the early years became less frequent, as fires were efficiently spotted and put under control. Routine air patrol replaced the fire tower. Helicopters are now used to deploy fire fighters, equipment, and supplies. New chemicals and tools have been developed to fight the flames, and huge bulldozers are used to prepare fire breaks. The administration of a major fire-control operation is complex and costly, with command posts, radio communications, airborne infrared sensors to map the progress of fires even through dense smoke, special weather forecasters, labor recruiters, personnel managers, and elaborate reporting routines, analyses, and reviews.

But forest fires are still difficult to suppress once they get out of control and spread over large areas. Their progress depends primarily on wind, temperature, humidity, and precipitation, on the abundance and character of the fuels, and on the topography and presence of natural fire breaks such as lakes or barren mountain tops. It is probably the case that many major fires are still "controlled" more by the exhaustion of fuel or by a change in the weather than by the efforts of man and his machines.

Meanwhile, many plant ecologists also saw fire primarily as the destroyer of the forest. When F.E. Clements dominated the field from 1905 to 1945, many were preoccupied with concepts of plant succession under stable climatic conditions in the absence of disturbances such as fire. Fire was viewed as an interruption of succession, external to the system. The search instead was for a predictable model of forest succession, leading to a climax that would reproduce itself ad infinitum until the climate or soils changed or geomorphic processes modified the landforms. The 
climax was visualized as a long-term equilibrium between the vegetation and a stable physical environment.

International critiques of Clements' concept of the climax led to adoptions, elaborations, modifications, or rejections in widely separated parts of the world, wherever ecologists were struggling to understand the often puzzling patterns of vegetational types (Whittaker 1953). A few of them recognized that temporary instabilities and perturbations were natural factors controlling the long-range patterns of vegetation, and that recurring fire could maintain such stability. Others studied intensively the details of plant succession after fire.

Loucks (1970) examined the theoretical effect of natural random perturbations on the diversity and community stability of a natural forest, pointing out that the elimination of such perturbations by man can cause an upset more severe than any previously experienced by the ecosystem. The present symposium offers some of the field evidence for the frequency of such a natural perturbation as fire on major forest ecosystems - the Great Lakes Forest, the Boreal Forest, and the forests of the Rocky Mountains and the Sierra Nevada. The field evidence is critical because it includes a firm framework of time and thus provides a factual rather than a theoretical basis for discussion of stability.

\section{THE TIME FACTOR IN SUCCESSION}

The key to understanding forest succession is knowledge of the time factor, for ecological succession is basically an historical subject. The traditional approach of plant ecologists in acquiring a time framework is to observe or measure the separate elements or stands of a forest mosaic that are thought to represent the various stages in succession, perhaps leading to some type of climax. Thus the short-lived jack pine [Pinus banksiana Lamb.] and aspen [Populus tremuloides Michx.] stands of the northern Great Lakes Forest might be seen as only stages in a succession to shade-tolerant fir-spruce-cedar-birch forest in the absence of fire. Occasionally circumstances might permit repeated measurements at the same site over a period of many years, to provide a highly specific picture of succession, but such opportunities are localized and short-term in relation to the lifetime of the forest type. Centuries would be required to document directly the complete forest successions in most regions, and such work is simply not being accomplished anywhere in the world.

The time dimension in studies of the elements of a mosaic can be most accurately determined when a definite starting time for succession can be identified. In the case of colonization and succession on abandoned river bars or on a recently deglaciated landscape, the starting time may be distinct, and the sequence from pioneer plants through various successional stages may be easily recognized. In the case of the complex mosaic that characterizes a fire-dependent forest, the starting times of the individual elements of the mosaic cannot easily be determined. Many elements may date from hundreds of years ago. Even when a severe fire occurs, some plants survive, so not all of the new growth starts from seed. Not only might single tall trees of red or white pine survive, but the root systems of other trees are adapted to send up shoots that grow profusely after a fire. In these cases, one should think not of a simple starting time but rather of a renewal of forest growth after an interruption.

In any case, reconstruction of long-time successional events in a forest mosaic simply on the basis of the modern forest composition encounters difficulties. Additional historical methods are needed. For forest succession under the influence of repeated fire, two approaches are available_ one covering the time range of a few hundred years, the other covering many thousands of years. Both perspectives are needed. 
First, the trees themselves, in their annual rings, may hold a record of fire history. When a fire is sufficiently severe it may kill all the trees, and at the same time it opens the area to light and provides a concentrated supply of nutrients in the ash, thereby encouraging the germination of seeds and the growth of shoots, resulting in a new stand of trees. The uniform age of the trees in such a stand thus may record the approximate date of the last major fire. On the other hand, if a fire is not severe enough to kill a tree, it may leave a scar on the trunk that is covered by subsequent ring growth but visible on cut sections of the trunk. Some trees carry several scars, each of which can be dated by ring counting. Usually, the fire-scar record confirms the age-class record. By these methods, the fire history of old forests can be traced for hundreds of years.

Beyond 300-500 yr in most regions one must go to another technique - the stratigraphic analysis of the pollen and charcoal content of lake sediments, preferably annually laminated sediments, which can provide a precise chronology. Charcoal analysis shows that fire has been an element in the forest ecosystem for thousands of years. The pollen content of the same sediment, which records primarily the regional rather than the local pollen rain, indicates that the forest mosaic as a whole has remained largely unchanged since shortly after the land was uncovered by the wasting ice sheet, while slight shifts in dominant tree types reflect minor climatic changes or tardy immigration from distant glacial refuges. In detail, of course, the composition of individual elements comprising the forest mosaic changes abruptly with each severe fire, and the composition of other elements changes gradually by succession between fires-for example, from pine to spruce and fir.

Thus the historical perspective afforded by tree-ring analysis and by charcoal and pollen analysis adds new dimension to the concept of climax. In a fire-dependent forest one may consider equilibria on two scales - a long- range equilibrium represented by the entire ecosystem, in which fire is the principal environmental factor, and a short-range equilibrium, or climax in Clements' sense, which is occasionally approached in local elements of the mosaic that have escaped fire for a long time, such as an island in a lake. In a fire-dependent forest, the Clementsian climax is rarely reached, although continuation of the present policy of fire suppression would make its attainment more likely.

Geomorphologists may recognize that this evaluation of the vegetational climax is similar in certain respects to recent views on the erosion cycle and the formation of peneplains. William Morris Davis, who dominated geomorphic theory from 1890 to 1935 , visualized a landscape as developing through successional stages of youth, maturity, and old age under conditions of crustal and climatic stability (Davis 1899). He conceived of the peneplain as the climax landform to which all stable landscapes must develop. It would not be surprising to find that Clements derived some inspiration from Davis as he developed his climax theory for vegetation along the same lines. In fact, in a sense the two concepts were brought together by Lucy Braun (1947) and other plant geographers in the Appalachian region, who wrote of a relic flora of Tertiary age on the Schooley peneplain. In this picture, crustal uplift interrupted the cycle of erosion and caused dissection of the peneplain, thereby initiating a new cycle but leaving remnants. At the same time the vegetational climax was interrupted, leaving behind relics coincident with the peneplain remnants.

After Davis the peneplain theory suffered criticism and rejection by many geomorphologists. The disagreements were first manifested by general disbelief that the crust and climate were stable enough for the landscape ever to reach its climax of erosional development. The criticism, started on a theoretical basis by Walther Penck (1924), came into focus with John T. Hack's well-reasoned presentation of a 
substitute theory of landscape development, in which he describes a "dynamic equilibrium" between the degradational forces (the weathering, soil creep, and stream erosion inherent in Davis's erosion cycle) and the opposing forces of rock resistance and crustal uplift (Hack 1960). The resulting landforms maintain a steady state of balance that is independent of time.

In a comparable way the concept of vegetational climax has been criticized and rejected by many ecologists, partly because of an inadequate basis to project the successional development far into the indefinite future under conditions of a stable environment. In systems like the northern conifer forests under consideration here, the environment is simply not stable in all of its factors. These difficulties can be met in part by recognizing that the mosaic of forest types represents a long-range equilibrium that depends on the recurrence of a major type of perturbation-fire. Some elements of the forest mosaic may succeed toward a climax, from youth to maturity and even to old age, while other elements are interrupted in the sequence by fire. As the locus of fire shifts through time from one element to another, the forest composition as a whole remains much the same, thus maintaining a stable ecosystem. Such an equilibrium can prevail for thousands of years, until climatic change, species migration, or some other new external factor is introduced to the system. Then in reaction to this change the system will adjust to a new equilibrium with a different overall forest composition, again with its own mosaic elements changing in a dynamic pattern as the short-range factors such as fire and succession exert their local influences.

\section{FIRE AS AN ECOSYSTEM PROCESS IN FIRE-DEPENDENT NORTHERN CONIFER FORESTS}

In his closing remarks, Symposium Chairman Charles F. Cooper made a plea for viewing fire as an ecosystem process, rather than continuing to treat it with case histories for particular organisms, communities, or ecosystems. He suggested we identify the general principles and then concentrate on regional variations and exceptions. We agree. To stimulate thinking, some of the principles that we see running through the symposium papers are briefly set down here. They still are restricted to the degree that we considered only factors, processes, and effects common to the conifer forests of western and northern North America. The list is also certainly incomplete. You are challenged to change or improve the framework, add to the list, and join the search for generalities and exceptions as suggested by Chairman Cooper.

\section{A. Fire as an Influence on the Physical- Chemical Environment}

1. Fires directly release the mineral elements as ash from the living and dead organic substances burned. The burned system components may include organic layers, litter, foliage, bark, wood, fruits, seeds, animals and their excrement, etc.

2. Fires may indirectly release still more mineral elements through increased decomposition rates of remaining organic layers and other remains, leaching or erosion of mineral soils, physical spalling of rocks and the subsequent breakdown of rock fragments, etc. The quantities involved in 1 and 2 are poorly known. They are certainly significant if the fires are intense and frequent. For example, the exfoliation of granite boulders and rock outcrops heated intensively by the burning of moss and lichens and other fuels, as manifested in the Little Sioux fire of 1971 in northern Minnesota, may be by far the most important rock-weathering process in the region. 
3. Some nutrients are volatilized, at least in part, for example nitrogen compounds.

4. Fires reduce plant cover shading the ground and thereby increase insulation. The effect varies with burn type (crown or ground fire) and intensity.

5. Increased insulation changes soil temperature and local climatic regimes. The effect varies with slope, aspect, latitude, elevation, soil moisture, soil properties, etc.

6. In northern Canada and Alaska permafrost may be thawed following fires, or conversely, during long periods between fires, the active layer may decrease in thickness or new permafrost layers may originate.

B. Fire as a Regulator of Dry-Matter Accumulation

1. Fires directly recycle the carbon of herbs and shrubs, and the foliage, bark, and wood of trees. Conversely, without fire, as the stand matures and decomposition fails to keep pace, these components gradually accumulate. The proportion of the dry matter consumed varies with fire type, intensity, and frequency. These in turn vary with many environmental factors.

2. Fires may consume the carbon in litter and humus layers and sometimes remove increments of peat. Conversely, in the absence of fire these layers increase to the extent that decomposition fails to balance accumulation. The imbalance is related to temperature, precipitation, evaporation, latitude, elevation, topography, and many local site factors.
3. Following severe fires the killed trees (snags) may constitute a large reservoir of dead organic matter.

4. Fires may stimulate increased net primary production through changes in the physical-chemical environment.

5. Fires may retard the accumulation of humus and peat for a period after burns through effects of soil nutrients, temperatures, and permafrost. The effect is complex because of interactions with the evapotranspiration balance and the groundwater levels on the sites where accumulation is most rapid.

\section{Fire as a Controller of Plant Species and Communities}

1. Fires may trigger the release of seeds (jack pine, lodgepole pine [Pinus contorta Douglas ex Loudon], several others).

2. Fires stimulate the flowering and fruiting of many shrubs and herbs.

3. Fires alter seedbeds. If litter and humus removal are substantial, large areas of bare soil, thin ash, or thin humus may be created. These influence germination and survival of many forest plants. Among trees benefiting from such seedbeds are most northern pines, Douglas fir [Pseudotsuga menziesii (Mirb.) Franco], giant sequoia [Sequoiadendron giganteum (Lindl.) J. Buchholz], some species of spruce [Picea spp.], and many others.

4. Fires stimulate vegetative reproduction of many woody and herbaceous species when the overstory is killed. These plants sprout from the root collar (birch [Betula spp.], maples [Acer spp.], oak [Quercus spp.], redwood, hazel, alders [Al- 
nus spp.], willows [Salix spp.], etc.), or root suckers (aspens).

5. Fires eliminate or temporarily reduce competition for moisture, nutrients, heat, and light. The effect may selectively favor some stand strata or components, or be total, depending on type of fire and intensity.

6. Fires may selectively eliminate part of a plant community (surface fires or partial overstory-kill).

7. Fire frequency (return interval) influences community composition and successional stage and controls overstory age for vegetation types reproduced by crown fires (jack pine, lodgepole pine, black spruce [Picea mariana (Mill.) Britton, Sterns \& Poggenb.], etc.).

8. Fire frequency regulates susceptibility of forests to blowdowns.

D. Fire as the Determinant of Wildlife Habitat Patterns, Populations

1. Fire increases foods for herbivores dependent on forage or browse plants that proliferate in early postfire successions (elk [Cervis spp.], deer [Odocoileus spp.], moose [Alces spp.], beaver [Castor spp.], hare [Lepus spp.], porcupine [Erethizon spp.], etc.).

2. Fire increases yields of many berry producing shrubs (favors bears, many birds, etc.).

3. Fire eliminates some forage plants characteristic of old forests for 50-100 yr-notably tree lichens and ground lichens in the north. It removes lichens used by barren-ground caribou [Rangifer tarandus groenlandicus (Borowski)] on winter ranges, and by woodland caribou [Rangifer tarandus caribou (Gmelin)] farther south.
4. Fire regulates many insect populations, some of which are important food sources for warblers, woodpeckers, etc. There may be increases or decreases in food availability, depending on prey and predator.

5. Fire controls the scale of the total vegetation mosaic through fire size, intensity, and frequency (the natural fire rotation), and influences the relative abundance of plant communities and successional stages. These determine habitat patterns for all herbivores, and therefore regulate their numbers to the extent that populations are habitat-limited.

6. Carnivores (wolf [Canis lupus L.], cougar [Puma concolor L.], coyote [Canis latrans Say], fisher [Martes pennanti Erxleben], mink [Mustela vision Schreber], marten [Martes americana turton], lynx [Lynx canadensis Kerr], eagles, hawks, etc.) are dependent on herbivores and therefore on the fire-created vegetative mosaic.

\section{E. Fire as Controller of Forest Insects, Parasites, Fungi, Etc.}

1. Fire directly terminates outbreaks of the spruce budworm [Choristoneura spp.], mountain pine beetle [Dendroctonus ponderosae Hopkins], and other insects, by eliminating their hosts over sizable areas.

2. Fire or the lack of it regulates the total vegetative mosaic, and the age structure of individual forest stands within it. These influence insect populations.

3. Insect outbreaks may create fuel concentrations that make largescale fires possible. Such fires then terminate the outbreak until the stands again attain susceptible 
ages. A self-perpetuating interaction may occur.

4. Fires temporarily eliminate such plant parasites as mistletoe on black spruce, lodgepole pine, and perhaps other species. It may also "sanitize" forests against other pathogens for a time. (We know little about such interactions yet.)

F. Fire as the Controller of Major Ecosystem Processes and Characteristics

1. Nutrient cycles and energy flow. In fire-dependent ecosystems fire is a major factor in nutrient cycling and energy flow. Rates and pathways are influenced by fire frequency and intensity. In the absence of fire, nutrient cycles and energy flow may be partially or severely blocked by incomplete decomposition of biomass. The accumulation of biomass in turn builds up fuel loads, which make lightning ignitions and high-intensity burns increasingly probable with the passage of time.

2. Succession. The natural fire rotation controls the total mosaic of stand age classes and successional stages on the landscape. Depending on return intervals, intensity, and fire type, it may also determine succession within stands.

3. Diversity. Fire prevents system-wide succession to species-impoverished climax stands by maintaining a mix of successional stages in the total vegetative mosaic. The spatial scale of the mosaic is determined by fire size, type of fire regime (surface or crown fires), and the natural fire rotation. Return intervals, intensity, and fire size together determine the pattern of stand ages and successional stages. These are the major factors determining system diversity on a gross scale, both for the plant communities and the animal side of the ecosystem. Fire also may be crucial in setting forest/non-forest ecotones, such as parkland/forest boundaries in the western mountains, forest/ tundra boundaries in the far north, and grassland/forest boundaries in the Canadian prairie provinces and elsewhere. Fire may also control the local occurrence of plants through interactions with soils, slope, aspect, elevation, etc. All of these factors influence diversity of the system as a whole. Fire can also simplify and impoverish individual stands floristically, but it is not clear that it had this result for total ecosystems in primeval times.

4. Productivity. Production is heavily linked to complete nutrient cycling. Fire recycles nutrients that might otherwise not move, and it influences soil temperatures and local climates. It prevents the accumulation of nutrients, dry matter, and energy in soil organic layers and peat strata, and it prevents permafrost encroachment. Periodic perturbations of the system by fire to achieve these effects seem necessary to the maintenance of longterm system productivity in many ecosystems, but we know far too little about this.

5. Stability. As noted under diversity, system-wide succession to impoverished climax stands is prevented by fire. Instead, a mix of successional stages, communities, and stand ages is maintained by periodic fire. This may produce a more stable system. Fire exclusion, for 
example, might cause dry matter (fuel) accumulations, which could lead to large-scale intense fires and unnatural effects on regeneration. An aged near-climax forest might also be far more susceptible to insect and disease outbreaks and to blowdowns. Its animal populations would be less diverse and probably less stable.

The symposium focused on at least seven general problems in understanding or describing fire-dependent conifer-forest ecosystems:

1. We need to understand more thoroughly the relative roles of lightning and man as fire factors in the primeval system. The key question is whether lightning alone is an adequate source of ignition to account for the observed extent of burning in given ecosystems. It is important to know how much the fire periodicity and the burn area were influenced by man in the period still recorded in the fire-scar and tree-ring records of existing virgin forests. These areas can provide the most direct estimates of fire's role. Evidence from tree rings, lake sediments, archaeological studies, and historical sources should be combined to attack this question.

2 . Studies are needed to elucidate the climatic patterns that produce major fire years in various regions. The actual history and degree of synchroneity of fire years over subcontinental regions should be documented. The latter is a straightforward problem in tree-ring analysis. The former calls for collaboration of tree-ring analysts, paleobotanists, and climatologists.

3. More work is needed to characterize the types of fire regimes that prevailed in various ecosystems, and to clarify the differences in ecosystems related to these regimes:
a. Long-interval crown-fire regimes
b. Short-interval crown-fire regimes
c. Long-interval surface-fire regimes
d. Short-interval surface-fire regimes sequoia stands the regime may have been a combination of a and $\mathrm{d}$.
e. All possible combinations of the above; for example, in giant

4. There is a need to define the natural fire rotations characteristic of various ecosystems to permit more precise comparisons of different systems, and to guide fire-management programs. Tree-ring analysis of fire-scarred trees can still determine the fire chronology in regions where remnants of the virgin forests exist. Tree-ring dating of stands, combined with mapping from aerial photographs or possibly even from ERTS satellite imagery, can be used to map out burn patterns where the scale is large and the patterns still clear. Actual fire records and lake sediment analyses can also help in some cases.

5. There is a need to document with hard data the relationship between fuel accumulation and time elapsed since the last fire for typical ecosystems and for vegetation types within systems. All fuel components in the ecosystem must be considered.

6. There is great need for quantitative data on the role of fire in nutrient cycles and energy flow in fire-dependent ecosystems.

7. Ecology needs a framework to deal simultaneously with and integrate the concepts of succession on the scale of local stands, and changes in the vegetation mosaic on an ecosystem-wide 
scale. Up to now there has been an unfortunate preoccupation with succession on the local scale, when it is the long-term system-wide changes that may have the greatest practical consequences. Such a conceptual framework should be worked out now for ecosystems where the system-wide patterns can still be determined from on-the-ground evidence available in intact virgin forest with discernible firecreated patterns. Present maps of the "natural" vegetation of North America (such as Küchler's 1964) show only the grand-scale theoretical patterns of the virgin forests. But such maps are really based on a dynamic, fire-created, fine-scale mosaic that could change dramatically with alteration of the fire factor in the system.

\section{MANAGEMENT OF NATURAL AREAS IN FIRE-DEPENDENT CONIFER FORESTS}

Many large sections of the western conifer forests have been included within national or provincial parks or have been officially designated as Wilderness Areas. In the Great Lakes area the only sizable remnant of virgin forest (the Boundary Waters Canoe Area of northeastern Minnesota) is also part of the wilderness system. These areas are all to be managed to preserve their natural character. Fire suppression has traditionally been the cornerstone of preservation. Policies and practices have been so successful that few major fires have occurred in such areas for many decades.

But the long-term consequences of fire suppression in nature reserves are now becoming clear, as shown in the discussion that precedes as well as in the several papers that follow. A managerial problem results from the gradual accumulation of dead timber and fine fuels on the forest floor, along with the proliferation of shrubs and understory trees. This buildup can provide the fuel necessary to carry flames to the overstory, killing many trees that otherwise might survive. Under natural conditions periodic fires remain close to the ground surface, and in many stands they may not often reach the canopy. Fuel buildup is aggravated in the Great Lakes Forest, where maturing balsam fir [Abies balsamaea (L.) Mill] and white spruce [Picea glauca (Moench) Voss] are killed by the spruce budworm, a native insect that under natural conditions may not have become epidemic so frequently as today, because periodic fires killed much of the fir and spruce before it became susceptible. In the Rocky Mountains a similar relationship exists between lodgepole pine and the mountain pine beetle. For the Sierran forests the fuel buildup problem is carefully described by Kilgore. Forest managers are understandably apprehensive of uncontrollable crown fires, not only because the standing timber is killed, but because of the very real danger of escape beyond the limits of the area. In many conifer-forest ecosystems crown fires were the agents of periodic natural stand renewal, however, and even these must somehow be provided for if the natural system is to survive.

Research on the ecological role of fire indicates that the stated objective of wilderness management, the preservation of the natural forest condition, is clearly not being accomplished under a policy of nearly total fire suppression. Forest composition will inevitably change, as fire-dependent species are replaced by climax species in Clements' sense. If total fire suppression prevailed for another century or two, the mosaic of forest types would be significantly different, and many of the types that characterize the northern conifer forests today, such as jack pine, red pine [Pinus resinosa Aiton], lodgepole pine, and aspen might virtually disappear from the system. The time scale for change is longer for Douglas fir, giant sequoia, and other long-lived western trees, but the trend is inexorable.

These implications of continued fire suppression are becoming apparent to many managers of wilderness areas. The problem was 
recognized in 1963 in the Leopold report on US National Park management, and the official policy for National Parks now permits a superintendent to allow lightning fires to burn if he anticipates no significant danger to man or property. Experience in Sequoia Kings Canyon National Park in the Sierra Nevada is recounted by Bruce Kilgore in this symposium. Prescribed fires for fuel reduction and for restoration of natural forest succession is also in the plans for certain other areas - they have been carried out for many years in Everglades National Park in Florida. In the National Forest system, the first attempts to allow lightning fires to run in virgin forest are now underway in the Selway-Bitterroot Wilderness Area in Idaho and Montana. The Boundary Water Canoe Area in Minnesota, which is characterized by a network of lakes and streams and other natural firebreaks, was the scene of a small prescribed fire in May 1973, which as an experiment in fuel reduction provided sound information on some of the logistics of conducting a spring fire. The extensive experience in fire fighting and fire technology that has been acquired over the decades by for- esters can now be applied to an objective different from fire suppression - an objective that in the long run is just as important for the health of the forest. With increasing public appreciation for wilderness areas, and the increasing level of understanding of forest ecology and particularly of the role of fire in natural forest succession, it seems likely that prescribed fires can be introduced safely in many wilderness areas, to return the virgin forests to some kind of natural fire regime. After more experience with prescribed fires, perhaps the time will come when wilderness managers can also allow many natural lightning fires to burn unchecked in areas where man or property is not endangered. Hopefully the papers presented in the symposium will clarify the role of fire in northern natural conifer forests and lead to an evaluation of management alternatives that will best preserve the wilderness for future generations.

Reprinted from Quaternary Research 3: 319-328,1973. Copyright@1973by University of Washington. All rights of reproduction in any form reserved.

\section{LITERATURE CITED}

Braun, E.L. 1947. Development of the deciduous forests of eastern North America. Ecological Monographs 17: 211-219. doi: 10.2307/1943265

Davis, W.M. 1899. The geographical cycle. Geographical Journal 142: 487-504. Also, pages 249-278 in: D.W. Johnson, editor. Geographical Essays (1954). Dover, New York, New York, USA.

Hack, J.T. 1960. Interpretation of erosional topography in humid temperate regions. American Journal of Science 258A: 80-97.

Küchler, A.W. 1964. Potential natural vegetation of the conterminous United States. American Geographical Society, Special Publication 36. Brooklyn, New York, USA.

Loucks, O.L. 1970. Evolution of diversity, efficiency, and community stability. American Zoologist 10: 17-25.

Penck, W. 1924. Morphological analysis of landforms. Translated by Hella Czeck and K.C. Boswell, 1953. St. Martin's Press, New York, New York, USA.

Whittaker, R.H. 1953. A consideration of climax theory; the climax as a population and pattern. Ecological Monographs 23: 41-78. doi: 10.2307/1943519 